\title{
Inhibitory role of oxytocin in psychostimulant- induced psychological dependence and its effects on dopaminergic and glutaminergic transmission
}

\author{
Jing-yu YANG ${ }^{1}$, Jia $\mathrm{QI}^{1,2}$, Wen-yan $\mathrm{HAN}^{1}$, Fang WANG ${ }^{1}$, Chun-fu WU ${ }^{1, *}$ \\ ${ }^{1}$ Department of Pharmacology, Shenyang Pharmaceutical University, Shenyang 110016 , China; ${ }^{2}$ National Institute of Drug Abuse, \\ National Institutes of Health, 21224, Baltimore, MD, USA
}

\begin{abstract}
Psychostimulants are frequently abused as a result of their stimulatory effects on several neurotransmitter systems within the central nervous system. Both dopaminergic and glutaminergic neurotransmissions have been closely associated with psychostimulant dependence. In addition to its classical endocrine function in the periphery, oxytocin, an important neurohypophyseal neuropeptide in the central nervous system, has a wide range of behavioral effects, including regulating drug abuse. The present paper reviews the progress of research into the role of oxytocin in reducing psychostimulant-induced psychological dependence and the mechanisms by which oxytocin mediates its effects.
\end{abstract}

Keywords: psychostimulants; oxytocin; cocaine; methamphetamine; dopamine; glutamate

Acta Pharmacologica Sinica (2010) 31: 1071-1074; doi: 10.1038/aps.2010.140; published online 23 Aug 2010

\section{Introduction}

Psychostimulants, also called psychoactive drugs, interfere with a variety of neurotransmitter systems, receptor families and signaling pathways to induce dependence, sensitization, and withdrawal. Both the dopaminergic and the glutaminergic neurotransmitter systems have received considerable attention over the past few decades. For instance, the mesolimbic dopamine (DA) system, which originates in the ventral tegmental area, contributes at least partially to the reinforcing effects of many abused drugs ${ }^{[1-5]}$. In addition, the glutaminergic system, which has projections from the prefrontal cortex (PFC) to the ventral tegmental area (VTA $)^{[6]}$, has also been shown to be involved in drug reward behaviors, such as conditioned place preference $(\mathrm{CPP})^{[7]}$ and behavioral sensitization $(\mathrm{BS})^{[8-11]}$.

Oxytocin (OT), a neurohypophyseal neuropeptide that is synthesized and released from magnocellular neurosecretory cells of the paraventricular nucleus (PVN) and supraoptic nucleus (SON) in the hypothalamo-neurohypophyseal system, has a wide range of behavioral effects in addition to its classical peripheral endocrine function. It has been demonstrated that OT can influence the development of tolerance to, dependence

\footnotetext{
* To whom correspondence should be addressed.

E-mail chunfuw@gmail.com

Received 2010-06-10 Accepted 2010-07-20
}

on, and reinstatement of abused drugs ${ }^{[12-18]}$. For instance, OT has been shown to inhibit tolerance and cross-tolerance to some opioid substances ${ }^{[13]}$ and to mitigate withdrawal symptoms. It has also been shown to block several addictionrelated behaviors induced by opioids or psychostimulants in rodents ${ }^{[14-18]}$. In addition to the research investigating the effects of OT on addiction-related behaviors, other lines of research have focused on the neurochemical mechanisms by which OT modulates psychostimulant-induced behavioral effects $^{[17]}$.

The present paper reviews the inhibitory role of OT in psychostimulant dependence and presents the current knowledge of its mechanism of action, including a review of two of the primary neuronal systems through which OT is thought to mediate its effects.

\section{Effects of OT on behavioral changes induced by psycho- stimulants}

Psychostimulant administration often induces marked behavioral changes, including hyperlocomotion and stereotyped behavior, among others. It has been reported that lateral ventricular injection of OT causes a dose-dependent attenuation of cocaine-induced sniffing ${ }^{[19]}$ and enhances cocaine-induced behavioral sensitization. In contrast, OT does not change the stereotyped behavior induced by methamphetamine $(\mathrm{MAP})^{[20]}$. Intracerebroventricular admin- 
istration of an OT receptor antagonist inhibits the effects of peripheral OT injection on morphine tolerance and heroin selfadministration, suggesting that the primary site of OT action is within the central nervous system (CNS) ${ }^{[16]}$.

\section{Effect of OT on psychostimulant-induced behavioral change in rodents}

By binding to OT receptors located in the limbic-forebrain areas, OT significantly inhibits the hyperactivity induced by psychostimulants possibly through the mechanism associated with the dopaminergic system ${ }^{[17,20,21]}$. Furthermore, microinjection of OT into the central amygdala and the bed nucleus of the stria terminalis results in an inhibition of aggressive behavior in lactating female rats ${ }^{[2]}$. Results have shown that acute MAP administration significantly increases locomotor activity in mice, an effect that can be inhibited by intracerebroventricular administration of OT. Furthermore, atosiban (Ato), a specific blocker of OT receptor, markedly attenuates the inhibitory effect of OT on MAP-induced hyperactivity ${ }^{[17]}$.

Repeated intermittent administration of psychostimulants causes an increase in their psychomotor stimulating effects and induces long-term hyperactivity ${ }^{[23,24]}$. As shown in Table 1, OT has multiple effects on behavioral changes induced by psychostimulants, such as behavioral sensitization, stereotyped behavior, and self-administration (SA). Sarnyai et al have demonstrated that a subcutaneous injection of OT following cocaine administration increases cocaine-induced BS, whereas a prophylactic injection of OT inhibits the behavioral tolerance of rats to cocaine ${ }^{[20,25]}$. Carson et al reported that OT dose-dependently reduced MAP SA and almost completely

Table 1. Effect of oxytocin on behavioral changes induced by psychostimulants.

\begin{tabular}{lccc}
\hline \multicolumn{1}{c}{ Behavior change } & \multicolumn{2}{c}{ SCffect of OT } & $\begin{array}{c}\text { Sites of } \\
\text { action }\end{array}$ \\
\hline $\begin{array}{l}\text { Cocaine } \\
\text { Locomotor hyperactivity }\end{array}$ & $\begin{array}{c}\text { Inhibition } \\
\text { Inhibition }\end{array}$ & - & - \\
$\begin{array}{l}\text { Stereotyped behavior } \\
\text { Tolerance }\end{array}$ & $\begin{array}{c}\text { Inhibition } \\
\text { Inhibition }\end{array}$ & $\begin{array}{c}\text { Inhibition } \\
\text { Inhibition (self- }\end{array}$ & Nac, TUO \\
Sensitization & Facilitation/ & administration) & vHPC, Nac \\
Self-administration & inhibition & - & - \\
Inhibition & - & - \\
Amphetamine & & & \\
Hyperlocomotion & No effect & Inhibition & \\
Stereotypy & No effect & - & - \\
Methamphetamine & & & \\
Locomotor hyperactivity & Inhibition & Inhibition & \\
Self-administration & Inhibition & & \\
\hline
\end{tabular}

Abbreviation: Nac, nucleus accumbens; TUO, tuberculum olfactorium; vHPC, ventral hippocampus; adapted from [16, 26, 33, 47]. blocked hyperactivity in response to $\mathrm{MAP}^{[26]}$.

Taken together, these results suggest that OT can inhibit the behavioral changes induced by psychostimulants in rodents.

Effect of OT on MAP-induced conditioned place preference in mice

The CPP paradigm, which contains several phases, including acquisition, expression, extinction and reinstatement of addiction, is thought to provide a reliable indication of the rewarding properties of drugs in animals ${ }^{[27]}$. Moreover, the extinction preference for the drug-paired environment can be reinstated by either drug priming or stress ${ }^{[28]}$. Numerous studies have demonstrated that MAP reliably induces a CPP in mice. Our previous studies have shown that intracerebroventricular injections of OT significantly attenuate the acquisition of CPP induced by MAP and block the reinstatement of CPP induced by restraint stress. In contrast, neither CPP expression nor CPP reinstatement induced by priming with MAP is influenced by $\mathrm{OT}^{[18]}$. Typically, MAP-induced CPP persists until at least the seventh day after the last drug-pairing session, but OT shows an extinction-accelerating effect on MAP-induced CPP, which can be attenuated significantly by Ato ${ }^{[18]}$. Taken together, these results indicate that OT exerts inhibitory effect on specific stages of MAP-induced CPP via the OT receptor.

\section{Effect of OT on the CNS levels of DA and glutamate induced by psychostimulants}

Recent studies have demonstrated that the synaptic plasticity of dopaminergic and glutaminergic neurons plays a key role in psychostimulant abuse and relaps $\mathrm{e}^{[29,30]}$. Lines of evidence showed that the suppressive effect of OT on psychostimulantsinduced behavioral changes ${ }^{[15-18]}$. Therefore, it seems reasonable that the inhibition of excessive release of glutamate (Glu) and DA by OT in relevant brain regions may contribute to the interruption of psychological dependence on psychostimulants.

Effect of OT on the levels of DA and its metabolites in different brain regions

It is well established that the mesolimbic DA system, including the VTA, plays an essential role in the reinforcing actions of many drugs (including MAP). An overwhelming body of evidence indicates that DA is partially responsible for the reinforcing effects of many abused drugs ${ }^{[5]}$. Several dopaminergic nuclei, particularly the nucleus accumbens (NAc), have been shown to be involved in psychostimulant reinforcement.

Over the last few decades, regulation of the pathophysiological process of drug dependence by OT had been shown to be partially mediated by its effects on dopaminergic function. Furthermore, OT decreases DA release and DA receptor binding in the mesolimbic dopaminergic system ${ }^{[18]}$. Moreover, evidence suggests that concurrent activation of OT receptors and DA $D_{2}$-type receptors in the NAc is essential for several functions to occur, which lead to various behavioral changes $^{[31]}$. It has been reported that OT antagonizes the increased utilization rate of DA (measured by DOPAC/DA 
and HVA/DA) in the NAc elicited by cocaine, suggesting that OT is likely to influence the behavioral effects of cocaine by affecting dopaminergic neurotransmission ${ }^{[21]}$. OT is thought to act as a neuromodulator of dopaminergic neurotransmission in limbic-basal forebrain structures and thus regulate adaptive processes in CNS leading to drug addiction ${ }^{[12,32]}$. Our studies have shown that OT prevents the behavioral effects of MAP, possibly through its attenuation of DA utilization in the striatum and NAc but not in the prefrontal cortex (PFC). The changes in DA turnover in the striatum and NAc induced by OT can be inhibited by Ato, suggesting that OT exerts its action through its receptor in striatum and $\mathrm{NAc}^{[17,33]}$.

\section{Effect of OT on glutamate levels in different brain regions}

Glutaminergic neurons and projections in the CNS have received considerable attention because of their involvement in drug-reward-related behaviors, such as $\mathrm{SA}^{[34]}$ and $\mathrm{CPP}^{[7]}$. Previous studies have demonstrated that the glutaminergic system in the mPFC, hippocampus, striatum and NAc is involved in morphine dependence and withdrawal ${ }^{[35]}$. In addition, it has been shown that glutaminergic neurotransmission in the VTA, PFC and NAc is necessary for cocaineinduced reinstatement ${ }^{[36-39]}$.

Previous data have shown that OT inhibits Glu activation by binding to OT receptors in the spinal cord and that prior OT application blocks the increased neuronal firing rate produced by Glu in antinociceptive progress, indicating that Glu may also be related to the effect of OT on dependence induced by abused drugs ${ }^{[40-43]}$. Our studies have shown that OT markedly inhibits the incease of extracellular Glu levels induced by restraint stress in mice exhibiting CPP but not those induced by MAP priming, and the administration of Ato attenuates the effects of OT on the changes in Glu levels ${ }^{[18]}$. Therefore, these findings suggest that OT inhibits drug-reward-related behaviors induced by MAP via the OT receptor and that OT blocks the reinstatement of $\mathrm{CPP}$, at least partially, by interfering with the glutaminergic system in the $\mathrm{mPFC}$.

\section{Effect of OT on NMDAR1 expression induced by psycho- stimulant drugs}

Although a few studies have shown that OT is able to affect the binding of some neurotransmitters to their receptors ${ }^{[35]}$, little is known regarding OT's effect on neurotransmitter receptor expression. NMDA receptors are known to be involved in drug addiction. Our studies have demonstrated that the expression of the NMDAR1 subunit in PFC was increased by acute MAP and MAP-challenging relapse and decreased by MAP withdrawal, indicating that NMDA receptor function in PFC may be partially associated with MAP-induced neurobehavioral changes. No significant difference in NMDAR1 expression was observed in the hippocampi of mice after treatment with MAP. Furthermore, each of these changes in NMDAR1 expression in the PFC could be significantly attenuated by $\mathrm{OT}^{[4-47]}$. These findings indicate that OT attenuates the changes in glutaminergic neurotransmission induced by MAP, partially via its effect on NMDAR1. Whether these effects of OT on NMDAR1 expression are related to its inhibition of MAP-induced psychological dependence has not been determined.

\section{Conclusion and prospects}

In recent decades, increasing evidence has shown that OT plays an important role in psychostimulant dependence via its actions on OT receptors in several brain regions. Although the mechanisms underlying the effects of OT are not clear, it appears that the ability of OT to modulate MAPinduced psychologically dependent behavior such as BS, $\mathrm{CPP}$ and SA, is closely related to its effects on dopaminergic neurotransmission in mesolimbic regions and its effects on glutaminergic neurotransmission in the forebrain.

Therefore, the present review suggests that OT might be a potential candidate for the prevention and treatment of neurological disorders induced by psychostimulants. Further elucidating the mechanism of action of OT in regulating psychostimulant dependence may highlight its potential as a novel pharmacotherapy for drug craving.

\section{Acknowledgements}

This research was partially supported by the Project of Key Laboratory for New Drug Screening and Key Laboratory for Pharmacodynamics of Liaoning Province, the Outstanding Youth Fund of Liaoning province, and the National Key Scientific Project for New Drug Discovery and Development (2009ZX09301-012), 2009-2010, China.

\section{Abbreviations}

Ato, Atosiban; BS, behavioral sensitization; CNS, central nervous system; CPP, conditioned place preference; DA, Dopamine; Glu, Glutamate; HPA, hypothalamo-pituitary-adrenal; MAP, Methamphetamine; $\mathrm{mPFC}$, medial prefrontal cortex; NAc, nucleus accumbens; NMDA, $N$-methyl- $D$-aspartate; OT, Oxytocin; PFC, prefrontal cortex; SA, self-administration; $\mathrm{TH}$, tyrosine hydroxylase; VTA, ventral tegmental area; TUO, tuberculum olfactorium; vHPC, ventral hippocampus.

\section{References}

1 Dackis CA, Gold MS. "Addictiveness of central stimulants". Adv Alcohol Subst Abuse 1990; 9: 9-26.

2 Wise RA, Bozarth MA. A psychomotor stimulant theory of addiction. Psychol Rev 1987; 94:469-92.

3 Koob GF. Neural mechanisms of drug reinforcement. Ann NY Acad Sci 1992; 654: 171-91.

4 Wise RA. Dopamine, learning and motivation. Nat Rev Neurosci 2004; 5: 483-94.

5 Koob GF, Caine SB, Parsons L, Markou A, Weiss F. Opponent process model and psychostimulant addiction. Pharmacol Biochem Behav 1997; 57: 513-21.

6 Taber MT, Das S, Fibiger HC. Cortical regulation of subcortical dopamine release: mediation via the ventral tegmental area. J Neurochem 1995; 65: 1407-10.

7 Zavala AR, Weber SM, Rice HJ, Alleweireldt AT, Neisewander JL. Role of the prelimbic subregion of the medial prefrontal cortex in acquisition, extinction, and reinstatement of cocaine-conditioned place preference. Brain Res 2003; 990: 157-64. 
Pharmacol Biochem Behav 2000; 66: 559-61.

8 Hao Y, Yang JY, Wu CF, Wu MF. Pseudoginsenoside-F11 decreases morphine-induced behavioral sensitization and extracellular glutamate levels in the medial prefrontal cortex in mice. Pharmacol Biochem Behav 2007; 86: 660-6.

9 De LM, Oliveira SB, Reisser A, Farrell M. Pharmacological treatment of cocaine dependence: A systematic review. Addiction 2002; 97: 931-49.

10 Kreek M, Laforge K, Butelman E. Pharmacotherapy of addictions. Nature 2002; 1: 710-26.

11 Shearer J, Gowing L. Pharmacotherapies for problematic psychostimulant use: A review of current research. Drug Alcohol Depen 2004; 23: 203-11.

12 Sarnyai Z, Kovacs GL. Role of oxytocin in the neuroadaptation to drugs of abuse. Psychoneuroendocrino 1994; 19: 85-117.

13 Kovacs GL, Van Ree JM. Behaviorally active oxytocin fragments simultaneously attenuate heroin self-administration and tolerance in rats. Life Sci 1985; 37: 1895-900.

14 Krivan M, Szabo G, Sarnyai Z, Kovacs GL, Telegdy G. Oxytocin blocks the development of heroin-enkephalin crosstolerance in mice. Pharmacol Biochem Behav 1992; 43: 187-92.

15 Krivan M, Szabo G, Sarnyai Z, Kovacs GL, Telegdy G. Oxytocin blocks the development of heroin-fentanyl crosstolerance in mice. Pharmacol Biochem Behav 1995; 52: 591-4.

16 Sarnyai Z. Oxytocin and neuroadaptation to cocaine. Prog Brain Res 1998; 119: 449-66.

17 Qi J, Yang JY, Song M, Li Y, Wang F, Wu CF. Inhibition by oxytocin of methamphetamine -induced hyperactivity related to dopamine turnover in the mesolimbic region in mice. Naunyn-Schmiedeberg's Arch Pharmacol 2008; 376: 441-8.

18 Qi J, Yang JY, Wang F, Zhao YN, Song M, Wu CF. Effects of oxytocin on methamphetamine-induced conditioned place preference and the possible role of glutamatergic neurotransmission in the medial prefrontal cortex of mice in reinstatement. Neuropharmacology 2009; 56: 856-65.

19 Sarnyai Z, Babarczy E, Krivan M, Szabo G, Kovacs GL, et al. Selective attenuation of cocaine-induced stereotyped behaviour by oxytocin: putative role of basal forebrain target sites. Neuropeptides 1991; 19 : 51-6.

20 Sarnyai Z, Biro E, Babarczy E, Vecsernyes M, Laczi F, et al. Oxytocin modulates behavioural adaptation to repeated treatment with cocaine in rats. Neuropharmacology 1992; 31: 593-8.

21 Kovacs GL, Sarnyai Z, Barbarczi E, Szabo G, Telegdy G. The role of oxytocin-dopamine interactions in cocaine-induced locomotor hyperactivity. Neuropharmacology 1990; 29: 365-8.

22 Angelica RC, Anderlise B, Gabriela AM, Pereira AB. Lucion effects of oxytocin microinjected into the central amygdaloid nucleus and bed nucleus of stria terminalis on maternal aggressive behavior in rats. Physiol Behav 2005; 85: 354-62.

23 Stewart J, Badiani A. Tolerance and sensitization to the behavioral effects of drugs. Behav Pharmacol 1993; 4: 289-312.

24 Hyman SE. Addiction to cocaine and amphetamine. Neuron1996; 16: 901-4.

25 Zoltán S, Gyula S, Gábor LK, Gyula T. Opposite actions of oxytocin and vasopressin in the development of cocaine-induced behavioral sensitization in mice. Pharmacol Biochem Behav 1992; 43: 491-4.

26 Carson DS, Cornish JL, Guastella AJ, Hunt GE, McGregor JS. Oxytocin decreases methamphetamine self-administration, methamphetamine hyperactivity, and relapse to methamphetamine-seeking behaviour in rats. Neuropharmacology 2010; 58: 38-43.

27 Bardo MT, Bevins RA. Conditioned place preference: what does it add to our preclinicalunderstandingof drug reward? Psychopharmacology 2000; 153: 31-43.

28 Parker LA, McDonald RV. Reinstatement of both a conditioned place preference and a conditioned place aversion with drug primes. 2003; 171-81. 126-37.
29 Pierce RC, Kumaresan V. The mesolimbic dopamine system: the final common pathway for the reinforcing effect of drugs of abuse? Neurosci Biobehav Rev 2006; 30: 215-38.

30 Brigner C, Nordenankar K, Martin L, Mendez JA, Smith C. VGLUT2 in dopamine neurons is required for psychostimulant-induced behavioral activation. Proc Natl Acad Sci USA 2010; 107:389-94.

31 Liu Y, Wang ZX. Nucleus accumbens oxytocin and dopamine interact to regulate pair bond formation in female prairie voles. Neuroscience 2003; 121: 537-44.

32 Kovacs GL, Sarnyai Z, Szabo G. Oxytocin and addiction: a review. Psychoneuroendocrino 1998; 23: 945-62.

33 Sarnyai Z, Babarczy E, Kriván M, Szabó M, Kovács GL, et al. Selective attenuation of cocaine-induced stereotyped behaviour by oxytocin: Putative role of basal forebrain target sites. Neuropeptides 1991; 19: 51-6.

34 Goeders NE, Dworkin SI, Smith JE. Neuropharmacological assessment of cocaine self-administration into the medial prefrontal cortex. Pharmacol Biochem Behav 1986; 24: 1429-40.

35 Hao Y, Yang JY, Guo M, Wu CF, Wu MF. Morphine decreases extracellular levels of glutamate in the anterior cingulate cortex: an in vivo microdialysis study in freely moving rats. Brain Res 2005; 1040 : 191-6.

36 Amano T, Matsubayashi H, Sasa M. Hypersensitivity of nucleus accumbens neurons to methamphetamine and dopamine following repeated administrations of methamphetamine. Ann NY Acad Sci 1996; 801: 136-47.

37 Broom SL, Yamamoto BK. Effects of subchronic methamphetamine exposure on basal dopamine and stress-induced dopamine release in the nucleus accumbens shell of rats. Psychopharmacology 2005; 181: 467-76.

38 Izawa J, Yamanashi K, Asakura T, Misu Y and Goshima Y. Differential effects of methamphetamine and cocaine on behavior and extracellular levels of dopamine and 3,4-dihydroxyphenylalanine in the nucleus accumbens of conscious rats. Eur J Pharmacol 2006; 549: 84-90.

39 Pulvirenti L. Glutamate neurotransmission in the course of cocaine addiction. In: Herman BH. Glutamate and Addiction. Humana Press

40 Condes-Lara M, Maie IA, Dickenson AH. Oxytocin actions on afferent evoked spinal cord neuronal activities in neuropathic but not in normal rats. Brain Res 2005; 1045: 124-33.

41 Condes-Lara M, Rojas-Piloni G, Martinez-Lorenzana G, RodriguezJimenez J, Lopez-Hidalgo M, et al. Paraventricular hypothalamic influences on spinal nociceptive processing. Brain Res 2006; 1081:

42 Jo YH, Stoeckel ME, Freund-Mercier MJ, Schlichter R. Oxytocin modulates glutamatergic synaptic transmission between cultured neonatal spinal corddorsal horn neurons. J Neurosci 1998; 18: 2377-86.

43 Robinson DA, Wei F, Wang GD, Li P, Kim SJ, et al. Oxytocin mediates stress-induced analgesia in adult mice. J Physiol 2002; 540: 593-606.

44 Tatsushi O, Kinji Y. Facilitative modulation by NMDA receptors of vasopressin and oxytocin responses to osmotic stimuli in rats. Neurosci Res 1998; 31: 240.

45 Liu CY, Xie DP, Liu KJ, Zhou YQ, Liu JZ. Oxytocin microinjected into dorsal motor nucleus of the vagus excites gallbladder motility via NMDA receptor-NO-cGMP pathway. Brain Res 2005; 1032: 116-22.

46 Qi J, Wang LH, Yang JY, Wu CF. Effects of oxytocin on changes of $\mathrm{N}$-methyl-D-aspartate receptor 1 expression in prefrontal cortex and hippocampus of mice induced by methamphetamine. J Shenyang Pharm Univ 2008; 25: 825-30. Chinese.

47 Zoltán S, Gábor LK. Role of oxytocin in the neuroadaptation to drugs of abuse. Psychoneuroendocrinology 1994; 19: 85-117. 